\title{
What factors influence the collapse of trees retained on logged sites? A case-control study
}

\author{
P. Gibbons *, R.B. Cunningham, D.B. Lindenmayer \\ The Fenner School of Environment and Society, The Australian National University, Canberra ACT 0200, Australia \\ Received 4 April 2007; received in revised form 20 August 2007; accepted 29 August 2007
}

\begin{abstract}
Living trees (green trees) are intentionally retained on logged sites for many purposes such as wildlife conservation, future wood potential and aesthetics. Minimizing the risk that these trees collapse in the short-term will improve the chances that green-tree retention meets its objectives. In a retrospective case-control study, we identified factors significantly associated with the collapse of living trees retained on logged and slashburnt sites in south-eastern Australia within 8 years of harvesting. Trees with incomplete crowns or trees with at least one visible cavity were, on average, at three times greater risk of collapse relative to trees with complete crowns or no visible cavities, respectively. Trees with fire-scarring, trees retained greater than $50 \mathrm{~m}$ from intact forest or trees retained in isolation were, on average, around twice the risk of collapse relative to trees without fire-scarring, trees retained within $50 \mathrm{~m}$ of intact forest or trees retained among other trees, respectively. When considered jointly, the significant factors in a model predicting the collapse of retained trees - tree height, tree diameter, crown form - were all associated with the health of trees. Choosing the healthiest trees possible for fulfilling their function, protecting trees from damage (e.g. fire) and retaining trees near, or among, other trees are likely to reduce the risk of collapse among retained trees and thus contribute to the effectiveness of green-tree retention in logged eucalypt forests.
\end{abstract}

(C) 2007 Elsevier B.V. All rights reserved.

Keywords: Green-tree retention; Wildlife trees; Habitat trees; Mortality; Windthrow

\section{Introduction}

Trees are routinely retained on logged sites in native forests for a range of reasons, such as: wildlife conservation (Hope and McComb, 1994; Gibbons and Lindenmayer, 2002; Hyvarinen et al., 2006), aesthetics (Paquet and Belanger, 1997; Ribe, 2005), a source of seed and a future timber resource (Florence, 1996).

These trees may need to remain standing for considerable periods to meet the objectives of their retention. Mature trees are often retained to 'lifeboat' species that do not persist in young logging regrowth or to provide habitat features that cannot be recruited within the typical logging rotation (Lindenmayer and Franklin, 2002). Trees retained for aesthetic reasons must remain standing for at least the period it takes for the surrounding logged areas to regenerate sufficiently to provide a canopy cover, which was 15-20 years in coniferous forests in British Columbia (Paquet and Belanger, 1997). Trees

\footnotetext{
* Corresponding author. Tel.: +612 6125 2562; fax: +612 61250757. E-mail address: Philip.Gibbons@anu.edu.au (P. Gibbons).
}

retained as a future timber resource must remain standing for the period it takes for the tree to reach a merchantable age or the period between cutting events.

The early collapse of trees retained on logged sites will undermine the effectiveness of green-tree retention. Factors that predispose retained these trees to collapse in logged areas appear to relate to the dimensions and health of individual trees and the location of these trees relative to other trees. The height, diameter and crown architecture of trees can influence the vulnerability of trees retained after logging to windthrow (Scott and Mitchell, 2005). Stem damage and subsequent decay from fungi and invertebrates have been associated with the collapse of trees (Putz et al., 1983; Mattheck et al., 1995; Whitford and Williams, 2001). This damage can be exacerbated by the intensity (Gibbons et al., 2000a) and frequency (Whitford and Williams, 2001) of post-logging fire. Exposure to wind from the loss, or change in configuration, of surrounding vegetation (Raphael and Morrison, 1987; Chen et al., 1992; Mitchell et al., 2001) have been implicated with the collapse of trees. Windthrow can be exacerbated by shallow soil depth and high soil moisture (Fraser, 1962). 
Although eucalypt forests do not typically suffer severe windthrow events like some forest types of the northern hemisphere (Gordon, 1973; Savill, 1983), the rates of mortality and collapse observed among trees retained on logged sites in eucalypt are sufficient to undermine the objectives of green-tree retention-particularly in terms of perpetuating a supply of cavities for fauna which take longer to form ( $>120-240$ years) than the typical logging rotation ( $<80$ years) (Ball et al., 1999; Gibbons and Lindenmayer, 2002). In eastern Victoria Featherston (1983) observed that approximately $25 \%$ of retained trees died within 5 years of logging and slash-burning and in similar forest types in eastern Victoria and south-east New South Wales Gibbons et al. (2000a) found that trees retained on clearcut and slash-burnt sites died at average rates of 14-37\% and collapsed at average rates of $0.5-1.5 \%, 2-5$ years after logging. In montane ash forests Kefford (unpublished data, cited in Gibbons et al., 2000a) observed that $14-68 \%$ of trees retained on logged sites had died within 2-3 years after logging. In forests dominated by Jarrah (E. marginata) and Marri (Corymbia calophylla) in Western Australia, Whitford and Williams (2001) recorded relatively lower rates of collapse among trees retained after logging (2.0\% per decade), with slightly higher rates of collapse among larger trees (2.4\% per decade).

The aim of this study was to identify risk factors associated with the collapse of trees retained on logged sites in eucalypt forests in south-eastern Australia. We used these data to identify options for increasing the longevity of trees retained on logged sites and therefore improving the efficacy of green-tree retention.

\section{Methods}

This study was undertaken on logged sites in tall, lowland sclerophyll forest in East Gippsland, Victoria, south-eastern Australia $\left(37^{\circ} 20^{\prime}-37^{\circ} 50^{\prime} \mathrm{S}\right.$ and $\left.148^{\circ} 40^{\prime}-149^{\circ} 30^{\prime} \mathrm{E}\right)$. Mean annual rainfall ranges from approximately $720-1200 \mathrm{~mm}$. The dominant tree species in the study area were Silvertop Ash (Eucalyptus sieberi L.A.S. Johnson), White Stringybark (E. globoidea Blakely), Brown Stringybark (E. baxteri Benth.), Messmate (E. obliqua L'Her.) and Mountain Grey Gum ( $E$. cypellocarpa L.A.S. Johnson).

The silvicultural system employed in the study area was clearfelling or clearcutting in units of up to $40 \mathrm{ha}$. Trees are retained for seed and wildlife conservation in these forests at a rate of around $9 \mathrm{~m}^{2}$ of basal area ha ${ }^{-1}$ (Gibbons et al., 2000a) including large trees selected for wildlife conservation at a minimum rate of 5 per 15 ha. Logged areas are typically treated with a high-intensity burn in the autumn after harvesting to remove logging slash, promote seedfall and create a receptive seedbed.

Several approaches were considered for this study. A longitudinal study was considered to be beyond the available resources and time. A completely randomized design was rejected as too time consuming because of the number of plots required to obtain sufficient information on trees that had collapsed (large trees are generally retained in a low density and
$<1.5 \%$ of these are expected to collapse within 5 years of logging (see Gibbons et al., 2000a)). We therefore undertook a retrospective investigation. This was a matched case-control study (Collett, 1991) — a method typically employed in medical research in which patients that have a certain condition are compared with people who do not. In this study, collapsed trees (cases) were actively located within logged sites and randomly matched with standing trees (controls) for comparison.

In total, 17 logged sites each up to 40 ha and logged 4-8 years prior to the study were selected. Each site was divided into four strata representing the four quarters of the compass in which we actively searched for trees $\geq 50 \mathrm{~cm}$ DBH that had fallen (i.e. uprooted or snapped) after logging and slashburning. The first fallen tree located in each stratum that met these criteria was selected. These were the cases. Each fallen tree was then matched with one standing tree $\geq 50 \mathrm{~cm} \mathrm{DBH}$ randomly located in the same stratum. These were the controls. Whether a tree had fallen after logging and slash-burning was determined by the pattern of burning on the bole (i.e. evidence that the tree had burnt while standing), the presence of unburnt wood where the tree had snapped (indicating that the tree had collapsed after the slash burn), the persistence of small branchlets or leaves (indicating that the tree had collapsed relatively recently) and the relative position of fallen trees to material sawn during logging (indicating that the tree had fallen after logging). If we were unable to ascertain whether the tree had fallen before or after logging then the tree was not measured. A number of potential risk factors or explanatory variables were measured for each tree (Table 1).

For one to one matched data of this type, effects of variables and standard errors can be estimated using conditional logistic regression. This was achieved by: (1) considering data as having number of observations equal to the number of matched pairs, in this case 63 ; (2) calculating a set of new potential explanatory variables that are the differences between the case and control for each matched pair (for factors each unique difference between levels becomes the new level of the factor); and (3) estimating parameters in a conditional linear logistic regression model, where the response has a value of one for each observation and no constant term is fitted (Collett, 1991). In our analysis, all variables were first fitted separately and observed significance levels determined, and second, a 'best' set of risk factors was determined by sequentially dropping variables from the full model if their omission did not result in a significant change of deviance $(P<0.05)$.

Because a study of this nature is not random (we sought out the collapsed trees), we have effectively over-sampled the cases and therefore cannot calculate an unbiased probability of collapse among retained trees. However, we can analyse the conditions under which trees collapsed relative to trees that remained standing for each risk potential factor listed in Table 1. Parameter estimates and standard errors for a risk factor predicted using conditional logistic regression can be interpreted as logarithms of odds ratios (Collett, 1991). The odds ratio is the ratio of the odds of a tree collapsing if exposed to one level of a risk factor relative to the odds of a tree collapsing if exposed to the next level of the same risk factor. 
Table 1

Variables or risk factors measured for each fallen tree (case) and standing tree (control)

\begin{tabular}{|c|c|}
\hline Variable & Definition \\
\hline DBH (continuous) & Diameter at breast height over bark $(\mathrm{cm})$. \\
\hline Tree species (factor) & $\begin{array}{l}\text { Due to many collapsed trees being dead, it was only possible to divide species into three classes based on } \\
\text { bark type: (A) Silvertop Ash E. sieberi; (B) stringybark (i.e. E. globoidea, E. muelleriana, E. baxteri, } \\
\text { E. obliqua); or (C) Mountain Grey Gum E. cypellocarpa. }\end{array}$ \\
\hline Height (continuous) & Height in meters measured for fallen trees with a hip chain and for standing trees with a clinometer and hip chain. \\
\hline Butt damage (factor) & $\begin{array}{l}\text { Damage to the butt of the tree divided into two levels: (1) no damage, or localised butt damage confined to } \\
\text { sapwood and not as a result of burning; (2) sapwood or sapwood and heartwood removed from burning. }\end{array}$ \\
\hline Hollow (factor) & The presence or absence of visible cavities other than those in the butt of the tree. \\
\hline Stem form (factor) & Whether the stem showed evidence of growth stress: (1) straight; (2) bent or twisted. \\
\hline Crown form (factor) & $\begin{array}{l}\text { A broad estimate of the condition of the crown of the tree as one of three levels (for dead trees an estimate } \\
\text { of crown condition prior to dying based on residual dead branches): (1) complete or near complete; (2) } \\
\text { missing some sections; (3) missing large sections. }\end{array}$ \\
\hline Position on slope (factor) & The position of the tree on the slope: (1) ridge; (2) mid; or (3) lower. \\
\hline Distance to intact forest (factor) & Distance to the nearest adjacent unlogged forest or advanced regrowth measured as: $(1)<50 \mathrm{~m} ;(2)>50 \mathrm{~m}$. \\
\hline Tree density (factor) & $\begin{array}{l}\text { Number of standing trees within a } 30 \mathrm{~m} \text { radius qualitatively classified as: (1) none or very few; and } \\
\text { (2) a definite clump of trees. }\end{array}$ \\
\hline Slope (factor) & Slope measured in degrees with a clinometer and divided into two levels: (1) $0-16^{\circ}$; and (2) >16 \\
\hline Aspect (factor) & Azimuth measured with a compass: (F) flat; (N) $315-45^{\circ}$; (E) $45-135^{\circ}$; (S) $135-225^{\circ}$; (W) $225-315^{\circ}$. \\
\hline
\end{tabular}

Thus, an odds ratio of two for a risk factor means that, for every unit of increase in the level of that risk factor, the odds of a tree collapsing doubles and an odds ratio of 0.5 for a factor means that for every unit of increase in the level of that risk factor, the odds of a tree collapsing is reduced by half.

\section{Results}

One hundred and twenty six trees representing 63 matched pairs of standing and fallen trees were measured on 17 logged sites. The DBH of measured trees ranged from 51 to $191 \mathrm{~cm}$ with a mean of $101 \mathrm{~cm}$. The height of measured trees ranged from 9 to $45 \mathrm{~m}$ with a mean of $31 \mathrm{~m}$. Silvertop Ash comprised $45 \%$ of the trees observed, with the stringybark species (White Stringybark, Yellow Stringybark, Brown Stringybark and Messmate) collectively accounting for 53\% of the trees observed and Mountain Grey Gum accounted for the remaining $2 \%$.

The relative risk of trees collapsing on logged sites (Table 2) was significantly $(P \leq 0.05)$ associated with seven of the 12 variables when modeled individually. Trees with incomplete crowns were, on average, at 3.1 times greater risk of collapse relative to trees with complete crowns. Trees with fire-scarring were, on average, at 2.0 times the risk of collapse relative to trees without fire-scarring. The relative risk of trees collapsing on logged sites decreased by, on average, 9\% with every increase of tree height by a meter. Trees were, on average, at 2.6 times greater risk of collapse if they had at least one visible cavity relative to trees without visible cavities. The risk of collapse decreased by, on average, two-thirds for trees retained in the south and west aspects $\left(135^{\circ}-315^{\circ}\right)$ relative to trees retained in the north and east aspects $\left(315^{\circ}-135^{\circ}\right)$. Trees greater than $50 \mathrm{~m}$ from intact forest (i.e. the logging unit boundary) were, on average, at 1.9 times the risk of collapse relative to trees within $50 \mathrm{~m}$ of intact forest. And for every increase in tree diameter by $1 \mathrm{~cm}$, the average risk of collapse among retained trees increased by $1 \%$. There was evidence $(P<0.1)$ to indicate that the risk of collapse among retained trees was higher on steep relative to gentle slopes and the risk of collapse was lower if the trees were retained among clumps of trees relative to trees retained in isolation. The other factors (viz. tree species, stem form and topographic position) did not significantly $(P>0.1)$ contribute to the risk of collapse among trees retained on logged sites when modeled individually.

The explanatory variables that together best predicted the risk of collapse among retained trees were tree height, DBH and crown form (Table 3). The selected model predicted that relatively short trees with relatively large diameters and relatively poor crowns were at greatest risk of collapse (Fig. 1).

\section{Discussion}

Green-tree retention is a routine part of native forest silviculture in many countries (Lindenmayer and Franklin, 2002). Minimizing the risk of mortality among trees retained on

Table 2

The individual effect of each measured variable on the odds ratio (relative risk) that trees retained on logged sites would collapse

\begin{tabular}{lrll}
\hline Risk factor & $P$-value & $\begin{array}{l}\text { Odds ratio } \\
\text { (relative risk) }\end{array}$ & $\begin{array}{l}95 \% \text { confidence } \\
\text { interval for } \\
\text { odds ratio }\end{array}$ \\
\hline Crown form & $<0.001$ & 3.111 & $1.655-5.848$ \\
Fire-scarring at butt & 0.001 & 1.962 & $1.328-2.898$ \\
Tree height & 0.003 & 0.913 & $0.858-0.971$ \\
Tree hollows & 0.010 & 2.555 & $1.183-5.512$ \\
Aspect (SW compared & 0.031 & 0.333 & $0.108-1.032$ \\
$\quad$ with NE) & 0.039 & 1.866 & $0.947-3.677$ \\
Distance to intact forest & 0.050 & 1.013 & $0.998-1.029$ \\
Diameter (DBH) & 0.059 & 1.735 & $0.881-3.412$ \\
Slope & 0.061 & 0.451 & $0.167-1.219$ \\
Tree density & $>0.10$ & & \\
Tree species & $>0.10$ & & \\
Stem form & $>0.10$ & & \\
Topographic position & & & \\
\hline
\end{tabular}


Table 3

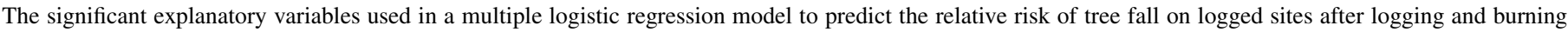

\begin{tabular}{|c|c|c|c|c|c|}
\hline Explanatory variable & Beta & S.E. & $P$-value & $\begin{array}{l}\text { Odds ratio } \\
\text { (relative risk) }\end{array}$ & $\begin{array}{l}95 \% \text { confidence interval } \\
\text { for odds ratio }\end{array}$ \\
\hline Tree height & -0.767 & 0.0378 & $<0.025$ & 0.926 & 0.859-0.999 \\
\hline Diameter (DBH) & 0.021 & 0.00985 & $<0.025$ & 1.021 & $1.001-1.041$ \\
\hline Crown form & 1.018 & 0.372 & $<0.005$ & 2.767 & $1.335-5.738$ \\
\hline
\end{tabular}

logged sites is important because these trees are often required to remain standing for long periods, or through multiple logging events, to meet the objectives of their retention.

The factors that significantly increased the relative risk that trees retained on logged sites collapsed within 4-8 years of logging related primarily to the dimensions and health of trees. The logistic regression model we selected to predict the risk that trees will collapse indicated that trees that were relatively short, with a relatively large DBH and a relatively poor crown were at greatest risk of collapse. That trees with a relatively large DBH and relatively short height were at greater risk of collapse appears to be contradictory to studies from the northern hemisphere that found trees with a higher heightdiameter ratio are more susceptible to collapse (Scott and Mitchell, 2005). However, our study was restricted to an investigation of relatively large ( $\geq 50 \mathrm{~cm} \mathrm{DBH})$ trees only, and we therefore potentially did not sample many trees with relatively high height-diameter ratios. The significant explanatory variables are associated with old or senescent trees suggesting that tree health is a key factor associated with the risk of collapse. Results from univariate analyses and other studies support this conclusion. Trees with no fire-scarring at the base or no visible cavities had a lower risk of collapse relative to trees with fire-scarring at the base or visible cavities, respectively. On logged sites in California and in Western
Australia, Morrison and Raphael (1993) and Whitford and Williams (2001), respectively found that retained trees burnt at their base had a relatively high likelihood of collapsing. In tall, wet eucalypt forests, Lindenmayer et al. (1990) observed that trees in the latter stages of senescence (i.e. trees with large diameters and partial crowns) were more likely to collapse than healthy trees.

Larger tree diameters, fire-scarring, crown health and the presence of cavities are significantly associated with the presence of stem decay (Gibbons et al., 2000b). A tree will fail when the ratio of the thickness of the stem wall to the stem's radius falls below 0.35 or where more than half of the circumference of the tree has been removed at the trunk base (e.g. from fire-scarring) (Mattheck et al., 1995; Gibbons et al., 2000a). These results suggest that the longevity of retained trees will be improved if trees without excessive stem decay or fire-scarring are selected for retention and these trees are protected from factors that can initiate decay (e.g. damage from logging machinery) or exacerbate existing damage to trees (e.g. fire).

We also examined whether factors relating to the location of trees represented significant risk factors. The variables aspect, slope, distance to intact forest (i.e. the logged area boundary) and whether the tree was retained in isolation or a clump of other trees were significant risk factors $(P<0.1)$. Trees
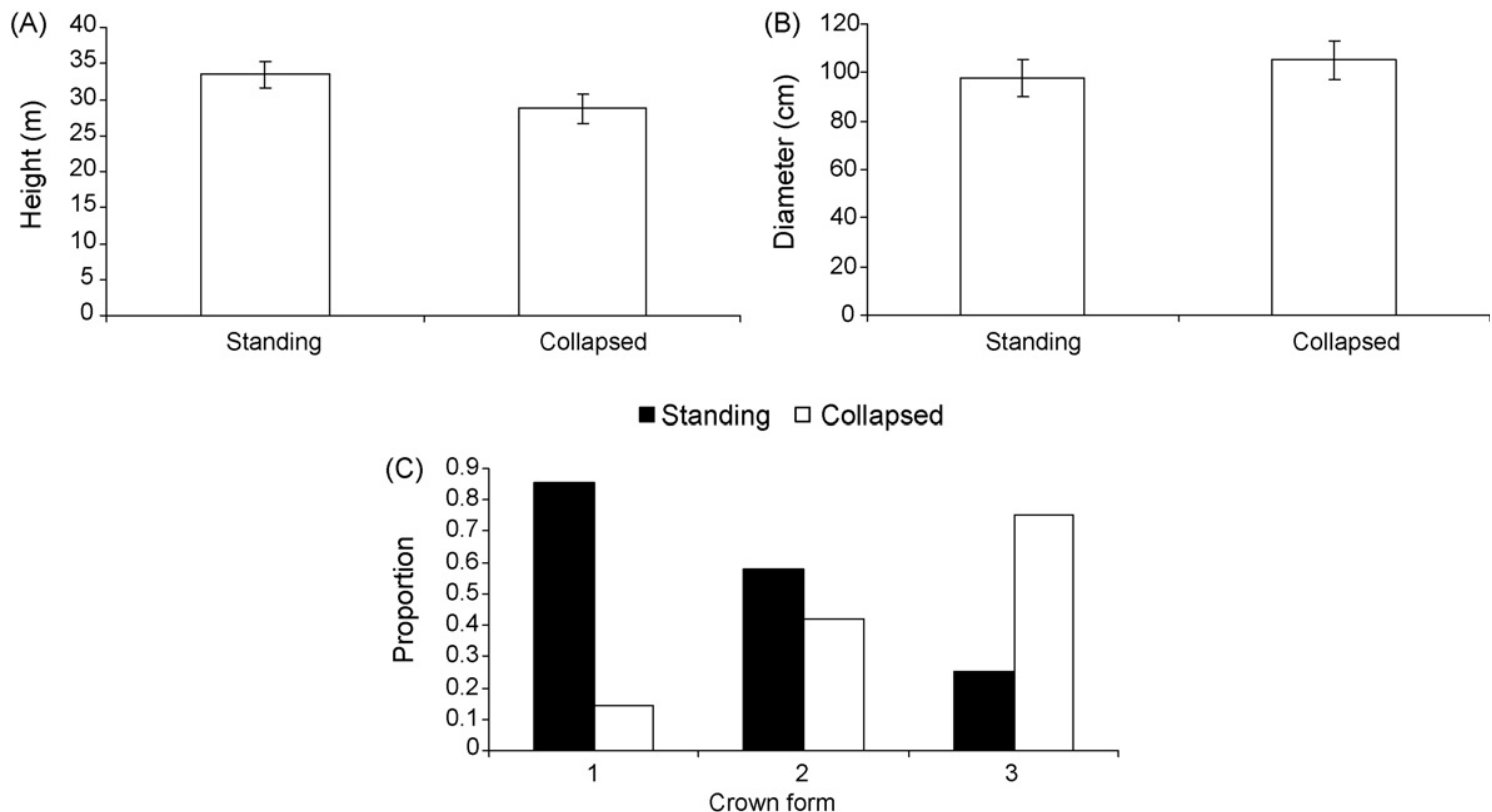

Fig. 1. The recorded: (A) mean height (m); (B) mean DBH (cm); and (C) proportion of trees with different crown form classes $(1=$ complete or near complete, $2=$ missing some sections, $3=$ missing large sections) for standing and collapsed trees examined in this study. Error bars are $95 \%$ confidence intervals. 
retained in north and east aspects had a higher risk of collapse relative to trees retained on south and west aspects. Topographic factors have been related to windthrow in some forests (Savill, 1983), probably because of their effect on wind speed and direction (Raphael and Morrison, 1987). Data on wind speed and direction recorded from two clearcut sites near the study area between 1989 and 1993 (Department of Natural Resources and Environment, unpublished data) indicated that the strongest winds were from the west to north west, whereas our results indicated greater relative risk of collapse on north and east aspects. The effect of aspect on tree fall cannot be explained by prevailing wind direction in this study. Either local relief or the configuration of the clearcut unit influences wind speed and direction and therefore data on wind speed and direction collected off-site are not comparable, or aspect influences collapse among trees via another mechanism. Gibbons et al. (2000a) suggested that the higher rate of mortality recorded among trees retained on northern aspects reflected the intensity that post-logging slash burns achieved on these aspects in the southern hemisphere. That trees were at greater risk of collapse on steep slopes could also be explained in terms of fire intensity that, other things being equal, is greatest on steeper slopes.

The position of trees relative to other trees affected the risk that trees would collapse. Trees retained greater than $50 \mathrm{~m}$ from intact forest had a higher risk of collapse relative to trees retained within $50 \mathrm{~m}$ from intact forest and trees retained in isolation had a higher risk of collapse relative to trees retained among other trees. This reflects the finding in other studies that trees are afforded protection from wind if retained among other trees (Savill, 1983; Beese and Bryant, 1999). However, this finding is not entirely consistent with studies from the northern hemisphere in which trees retained along the edge of logged units can be susceptible to windthrow (Chen et al., 1992; Mitchell et al., 2001) particularly where the boundary is long and straight or where thee are abrupt changes in direction in the cutting boundary (de Walle, 1983; Savill, 1983). Our results therefore cast doubt over windthrow being the principal mechanism of collapse among eucalypts retained on logged sites. Another explanation may be that trees retained closer to intact forest or other trees are more likely to remain unburnt, or burnt at lower intensity, during the post-logging slash-burn because it is towards the centre of the logged area where the intensity of the slash-burn is typically at its greatest and burns may be planned to avoid areas with retained trees.

Other variables not recorded in this study have been found to affect the collapse of trees including high soil moisture (Fraser, 1962; Cremer et al., 1977; Savill, 1983), and storm events (Gordon, 1973) which often combine to make trees uproot. No uprooted trees were recorded in this study, suggesting that soil moisture and rooting depth were not a major risk factor.

\section{Conclusion}

Our results suggest that the selection of the healthiest trees available for the purpose, and protecting these trees from damage, will be the most effective strategy to reduce the risk of their collapse within 4-8 years of logging in eucalypt forest. However, trees that possess several features that we found to be significant risk factors for collapse (e.g. large, senescent, cavity-bearing) are often preferentially selected for retention on logged sites because of their value as wildlife habitat and the fact that these features cannot be recruited within the typical logging rotation. Protecting these trees from further damage and retaining these trees among, or near, other trees, should be the principal strategies to reduce their risk of collapse. However, the inherent risk of collapse among large, senescent trees should be further managed by ensuring that the number of trees retained is greater than the minimum number required and sufficient large, healthy trees are retained each logging event so that new senescent trees can be recruited in the short-term should the existing trees collapse.

\section{Acknowledgements}

We thank Michael Vardon and Cindy Trewin for assisting with field work; Christine Donnelly for statistical computation; Olivia Gurley, Enrique Stucken, Peter Geary and Jan Radic from the Victorian Department of Sustainability and Environment for providing unpublished climatic information and logging history data; John Johnston for retrieving our bogged vehicle; and Michael Vardon, Tony Norton and Doug Mills for comments on earlier versions of this manuscript. This paper is dedicated to Peter Geary.

\section{References}

Ball, I.R., Lindenmayer, D.B., Possingham, H.P., 1999. A tree hollow dynamics simulation model. For. Ecol. Manage. 123, 179-194.

Beese, W.J., Bryant, A.A., 1999. Effect of alternative silvicultural systems on vegetation and bird communities in coastal montane forests of British Columbia. Can. For. Ecol. Manage. 115, 231-242.

Chen, J., Franklin, J.F., Spies, T.A., 1992. Vegetation responses to edge environments in old-growth Douglas Fir forests. Ecol. Apps. 2, 387-396.

Collett, D., 1991. Modelling Binary Data. Chapman and Hall, London.

Cremer, K.W., Myers, B.J., van der Duys, F., Craig, I.E., 1977. Silvicultural lessons from the 1974 windthrow in Radiata Pine plantations near Canberra. Aust. J. For. 40, 274-292.

de Walle, D.R., 1983. Wind damage around clearcuts in the ridge and valley province of Pennsylvania. J. For. 81, 158-160.

Featherston, G. R., 1983. Seed-tree health and survival at Maramingo and Reedy Creek pulpwood demonstration areas, East Gippsland, five years after harvesting. Research Branch Report. No. 219, Forests Commission of Victoria.

Florence, R.G., 1996. Ecology and Silviculture of Eucalypt Forests. CSIRO Publishing, Collingwood.

Fraser, A.I., 1962. The soil and roots as factors in tree stability. Forestry 35, 117-127.

Gibbons, P., Lindenmayer, D.B., 2002. Tree Hollows and Wildlife Conservation in Australia. CSIRO Publishing, Collingwood.

Gibbons, P., Lindenmayer, D.B., Barry, S.C., Tanton, M.T., 2000a. The effects of slash burning on the mortality and collapse of trees retained on logged sites in south-eastern Australia. For. Ecol. Mange. 139, 51-61.

Gibbons, P., Lindenmayer, D.B., Barry, S.C., Tanton, M.T., 2000b. The formation of hollows in eucalypts from temperate forests. Pac. Cons. Biol. 6 , 218-228.

Gordon, D.T., 1973. Damage from wind and other causes in mixed white fir-red fir stands adjacent to clearcuttings. USDA For. Serv. Res. Pap. PSW-90. Pacific Southwest Forest and Range Experimental Station. 
Hope, S., McComb, W.C., 1994. Perceptions of implementing and monitoring wildlife tree prescriptions on national forests in western Washington and Oregon. Wildl. Soc. Bull. 22, 383-392.

Hyvarinen, E., Kouki, J., Martikninen, P., 2006. Fire and green-tree retention in conservation of red-listed and rare deadwood-dependent beetles in Finnish boreal forests. Cons. Biol. 20, 1711-1719.

Lindenmayer, D.B., Franklin, J.F., 2002. Conserving Forest Diversity: A Comprehensive Multiscaled Approach. Island Press, Washington.

Lindenmayer, D.B., Cunningham, R.B., Tanton, M.T., Smith, A.P., 1990. The conservation of arboreal marsupials in the montane ash forests of the Central Highlands of Victoria, south-east Australia: II. The loss of trees with hollows and its implications for the conservation of Leadbeater's possum Gymnobelideus leadbeateri McCoy (Marsupialia: Petauridae). Biol. Cons. 54, 133-145.

Mattheck, C., Bethge, K., West, P.W., 1995. Breakage of hollow tree stems. Trees-struct. Funct. 9, 47-50.

Mitchell, S.J., Hailemariam, T., Kulis, Y., 2001. Empirical modeling of cutblock edge windthrow risk on Vancouver Island, Canada, using stand level information. For. Ecol. Manage. 154, 117-130.
Morrison, M.L., Raphael, M.G., 1993. Modelling the dynamics of snags. Ecol. Apps. 3, 322-330.

Putz, F.E., Coley, P.D., Lu, K., Montalvo, A., Aiello, A., 1983. Uprooting and snapping of trees: structural determinants and ecological consequences. Can. J. For. Res. 13, 1011-1020.

Paquet, J., Belanger, L., 1997. Public acceptability thresholds of clearcutting to maintain visual quality of boreal balsam fir landscapes. For. Sci. 43, 46-55.

Raphael, M.G., Morrison, M.L., 1987. Decay and dynamics of snags in the Sierra Nevada. California For. Sc. 33, 774-783.

Ribe, R.G., 2005. Aesthetic perceptions of green-tree retention harvests in vista views. The interaction of cut level, retention pattern and harvest shape. Landscape Urban Plan. 73, 277-293.

Savill, P.S., 1983. Silviculture in windy climates. For. Abstr. 44, 473-488.

Scott, R.E., Mitchell, S.J., 2005. Empirical modelling of windthrow risk in partially harvested stands using tree, neighbourhood, and stand attributes. For. Ecol. Manage. 218, 193-209.

Whitford, K.R., Williams, M.R., 2001. Survival of jarrah (Eucalyptus marginata Sm.) and marri (Corymbia calophylla Lindl. ) Habitat trees retained after logging. For. Ecol. Manage. 146, 181-197. 